\title{
Digital Fabrication Processes of Mass Customized Building Facades in Global Practice
}

\author{
Minjung Maing \\ The Chinese University of Hong Kong \\ maing@cuhk.edu.hk \\ Rodrigo Vargas \\ Universidad del Valle, Colombia \\ rodrigo.vargas@correounivalle.edu.co
}

\begin{abstract}
This paper describes the process of digital design and fabrication for customized building facades and effects from highly customized configurations in U.S., major manufacturing power of China, and emerging construction in Asia and South America. Case studies are presented to form comparisons of technology adoption to project workflow in these three global contexts. Although integration of digital fabrication has shown signs of success in U.S., traditional practices of limited digital information exchange are commonplace in Asia and South America. With focus on adoption of new fabrication tools, BIM and larger production capacity, the potential benefits of digital fabrication are imminent.
\end{abstract}

Keywords: Digital fabrication; Building facades; Mass customization; Curtain wall; BIM.

\section{Introduction}

Digital fabrication aims at automating the design-to-fabrication process by performing certain tasks faster and with more accuracy than traditional human workmanship design-to-fabrication translations. Combined with the phenomenon of globalization and universal access to cultural and technological knowledge, how project teams interact is changing workflow patterns. Learning from the automobile industry, mass customization offers benefits of controlled production costs within a larger range of design/geometry parametric variations, thus the appeal for more fluid processes of fabricating mass customizable building façade designs. Global practice of today cannot be sustained without the exchange of digital information instantaneously over continents allowing for scenarios of design, documentation, fabrication and installation to each happen at dispersed locations around the world. The only physical location constraint would be the location of the building itself.

Building Information Modeling (BIM), Parametric Modeling and Digital Fabrication are presented as structural concepts for the transformation of contemporary design and construction. While conventional CAD systems were developed as the optimization of the traditional design process, these new techniques and tools represent the search for the best role that Information Technology is able to perform in the field of architecture. This paradigm shift means a new approach for the design and construction industry in which processes, actors and tools are under examination.

The main advantage in using advanced means of digital representation lies not in the production or handling of complex or intricate shapes. The use of three-dimensional digital models, often including more than mere geometric definition, allows the processing of this information by other computerized equipment (KOLAREVIC 2003). In some cases this ability is used to assess and simulate the performance of buildings and their components. However, one of the most ambitious uses of digital media relates with digital manufacturing processes.

\section{Customized Building Façade Systems}

CAM technology, combined with parametric modeling techniques, challenges the modern paradigm of mass production, according to which objects should be identical to reduce manufacturing costs (Carpo, 2011) (Iwamoto, 2009). Digital manufacturing techniques, in which information is transferred directly from a computerized model to manufacturing equipment assume the possibility of expanding the production of non-identical objects without significantly increasing production costs - mass customization.

As long as contemporary architects are drawn to free-form geometries facilitated by advanced digital modeling tools, fabricators will be required to rapidly adapt their engineering and production processes to develop customized façade systems. CAM technology becomes necessary to facilitate the fabrication of a large number of different parts converging on assembly units. The use of CAM technology for fabrication of unitized facade systems basically implies the exchange of information between designers and machinery with low human intervention. 
One of the most adopted façade systems that have been tested with digital fabrication is glass facades also referred as glass and metal curtain wall systems. Curtain wall systems can be classified according with their design nature as standard or customized. Standard curtain walls are pre-engineered and have a pre-defined fabrication sequence, typically with smaller prefabricated components assembled on-site. In contrast, customized systems are developed for singular unitized design commissions that usually demand innovative approaches for design and fabrication under controlled factory conditions.

Standard curtain wall systems are less expensive to design and fabricate, hence their use is wide spread. Costs increase rapidly as intricate geometries and non-uniform facade configurations are proposed and the system is no longer able to use standard components. By definition, customized systems do not use predetermined components, making their design and fabrication more challenging and engineering-demanding.

China plays a significant role in global façade fabrication, especially in curtain wall systems which is one of most developed large mass produced façade system, with the last decade showing escalating market capture from Chinese manufacturers. With statistics such as curtain wall fabrication in China collectively providing more than $50 \%$ of global curtain wall use on projects, global practice in façade design will be affected the technology adeptness of designers with their Chinese fabricators. The efficiencies of digital fabrication will be essential to see global practices embracing production technologies and information management to enhance mass customization within a far-reaching integrated building design workflow.

In order to make comparative case study analysis the selected projects adopt customized curtain wall systems and how this façade component is considered in its design and fabrication is described in the following sections.

\section{Digital Fabrication for Building Facades in United States}

One of the recent projects in the United States that have shown a new promise to the use of digital model for automated fabrication is Beekman Tower by Gehry Partners in New York City. The complexity of the project is expressed on a larger number of steps: more numerous parties involved; highly sophisticated machinery; and more complex data being processed. Exchanges of information are consequently more intricate and require highly skilled agents for operating the digital tools and generating the documents.

Beekman Tower is a 76-story building located in downtown New York. It was designed by Architect Frank Gehry and constructed by Kreisler Borg Florman General Construction Company. Curtain wall system was engineered and fabricated by Permasteelisa North America (PNA). The building consists of a podium that houses a public school and health center offices; and a high rise tower that houses over 900 residential units. The tower is an undulating mass of glass-metal curtain wall system integrated with 16 gauge stainless steel panels.

Beekman's customized facade system comprises a traditional unitized glass and metal curtain wall for the wall's main barrier between inside and outside with an outer metal panel rainscreen that forms the undulating appearance. The glass and metal units are planar behind the metal rainscreen with insulated metal panels within the curtain wall behind the undulating panels.

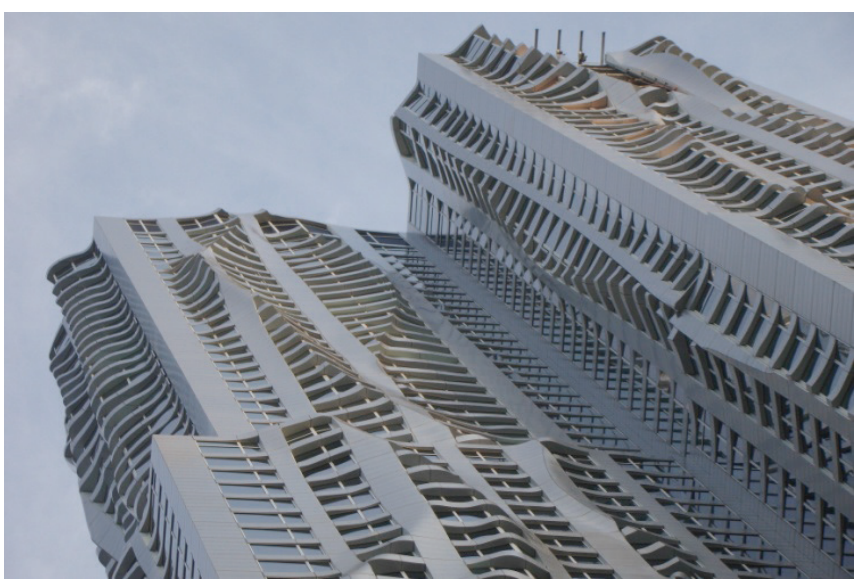

Figure 1: Beekman Tower. Gehry Partners - Permasteelisa NA. New York, NY. 2011

Concept design, design development and construction documents took over six years. Physical and digital models were iteratively built until the system was fully defined and tested on physical performance mock-ups. BIM coordination took place between all parties and the final product was a centralized model in which the curtain wall system was integrated. A design-assist scenario allowed PNA to get involved as consultant early in the conceptual design phase. During the design development PNA defined a series of rules for the geometric optimization of the surfaces based on the specifics of the fabrication process, which defined dimensional and geometric constraints for each unit of the façade system (Metals in Construction, 2011). Frank Gehry's IT consultant, Gehry Technologies (GT) developed scripting routines using finite element analysis to optimize the geometry of surfaces. $90 \%$ of the over 10.900 curtain wall panels was reduced from free form to single curved.

During earlier stages of the system design, PNA received 3D information from architects as Digital Project-CATIA models and provided them with design feedback using 2D CAD drawings. PNA also provided numeric data for structural analysis of the façade using Excel spreadsheets. Detailed curtain wall engineering was made with SolidWorks (subsidiary of Dassault Systems) models comprising parts and assembly unit information, from the CATIA surfacing models produced by architects as the base (Post, 2010).

PNA fabricated the primary curtain wall units in its facilities within the United States primarily from its Miami and Connecticut 
production lines. Exterior metal rain screen units, which required a more sophisticated fabrication process, were manufactured by a third party, Architectural Glazing Technologies (AGT), which developed software and machining code for PNA for the more complex curtain wall components. AGT produced a proprietary interface software between the SolidWorks API and the CNC 5-axis machinery and generated simulations of the fabrication sequences for verification.

A key objective to reducing fabrication costs was to use geometric optimization to maximize cold-bending, which was cheaper than mechanical rolling. 16-gauge stainless steel sheets with soft radii sections were cold formed; moderate sections were passed through a pyramidal roller and the tightest radii sections were made using cyclonic rollers. Geometric optimization of surfaces led to $70 \%$ of panels cold bent and only limited pieces with tighter geometries mechanically rolled. (Metals in Construction, 2011).

Due to the large amount of unique pieces of the system, all data for driving the CNC machinery was extracted directly from digital models to avoid extensive 2D shop drawing use. A unique notation system was adopted from the beginning to allow tracking of each component from production to installation using bar codes. This led to minimal physical drawings during installation on-site with only a diagrammatic set of drawings showing where each barcoded large curtain wall and metal panel unit was to be placed on the building. Beekman Tower has been presented by its developers as a successful experience in terms of budget and schedule control through the use of the design-assist scenario and BIM integration (Post, 2010).

\section{Digital Fabrication for Building Facades in Asia}

To examine technology adoptions in Asia, the most prominent location to consider is China where there has been a significant rise in construction in the last decades due to rapid urbanization. An indication of building façade fabrication that could give some insight into this high demand surge is China's growth in market share of curtain wall use and fabrication. In Synovate 2009 Report, China has surpassed its market share of the global curtain wall industry compared to US in 2012 where as in 2005 it was only about a third of US demand. China has seen a compound annual growth of $15 \%$ from $2005-2009$ in curtain wall market share and projects continued growth of over 20\% from 2009 to 2012. Chinese curtain wall manufacturers are among the top 5 global curtain wall fabricators and the one of top performing curtain wall fabricator companies (Italian-based Permasteelisa Group, also primary curtain wall fabricator for Beekman Tower project) operate two fabrication plants in China. So with global supply of curtain wall now primarily coming out of China, and global demand for curtain wall systems continuously growing on average $10 \%$ since 2005 , the question becomes how China curtain wall fabrication process integrates with design and fabrication.

A case study of CCTV Heaquarters in Beijing, China designed by OMA (completed 2008) showed that the design of the curtain wall system was heavily dependent on the simulated structural diagrid system along the perimeter of the building(Carroll 2008). However with dynamic modeling of the diagrid system and multilayered approach of the structure based on building load demands and façade integration, the fabrication process for the integrated curtain wall system was a traditional 2D shop drawing transfer from the design to fabrication. The curtain wall system was a standard glass and metal frame unitized system with variations to the metal frame to align with the diagrid diagonal members. The project came at a pivotal time during heavy construction demand in China driven by intense construction for the 2008 Beijing Olympic Games. Jangho Curtain Wall Company (one of the top 5 global curtain wall manufacturers) utilized several curtain wall fabricators through subcontracts to meet the fabrication demand and construction schedule, primarily relying on 2D shop drawing exchanges. The use of 2D shop drawing exchanges were in response to limited technology adoption and heavy reliance on cheap labor force within the industry.

One of the first implementation of extensive building information modeling (BIM) in China, is a 70-story office tower in Hong Kong named One Island East Tower designed by Wong and Ouyung Architects and completed in 2008. Although this was one of the first significant projects in Hong Kong to adopt BIM technologies in the building process, the main focus was to support the construction process. This was an owner-driven BIM initiative with the aim to use each project as drivers to further implement the BIM process on future projects within the owner's portfolio.

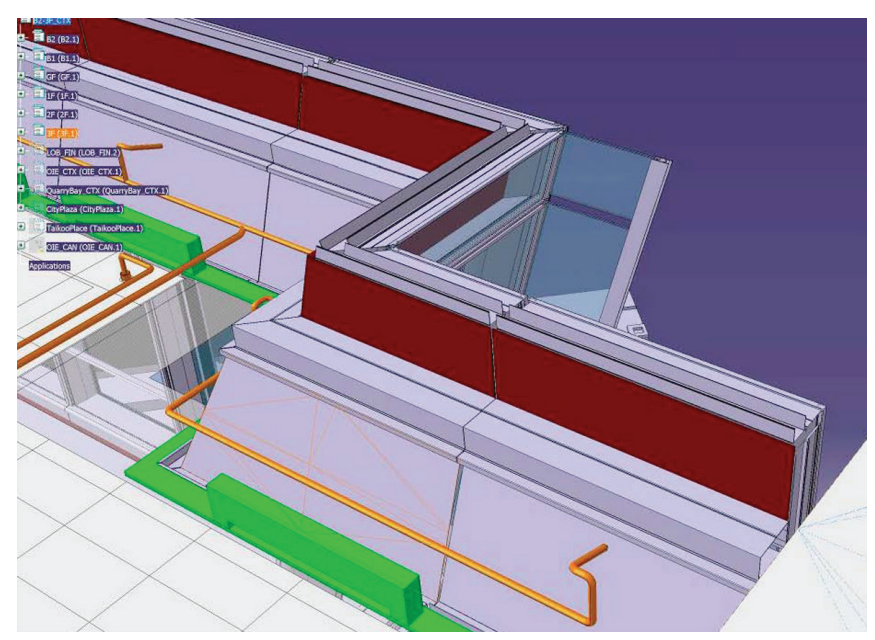

Figure 2: One Island East Tower. Hong Kong 2008

The façade of One Island East consists of glass and metal curtain wall system throughout most of the floors on all sides of the building. As a comparative case study to Beekman Tower, adoption of digital tools (Digital Project of Gehry Technologies) was highly emphasized to automate the transfer of digital information from conceptualization to construction through highly detailed construction digital models. However this approach had little effect on the traditional shop drawing based fabrication processes in China. The fabricator once tendered was given 3D 
visualization information but used shop drawings in the production line. The results on BIM adoption was better efficiency in construction, in particular coordination and installation of mechanical systems, early completion, cost savings and better coordination through detailed digital visualization and information transfer with contractors and designers. The adoption of digital fabrication was almost non-existent even with digital BIM models created with detailed façade component configurations.

The fabrication process does not differ for overseas projects undertaken by Chinese curtain wall fabricators. A recent built project, Highline 23 in New York City by Neil A. Denari Architects (completed 2011) with its customized curtain wall systems was studied as a comparative case. The façade on this project comprised of large glass and metal units and modeled in high level of detail for its unique connections and configuration. The façade model created in CATIA by façade consultants Front Inc. was intended primarily for clash detection with the steel structure, geometric optimization for fabrication and automated shop drawing generation. Given the conditions of fabrication in China, the fabrication level model was not able to be used for any form of digital fabrication by the fabricator.

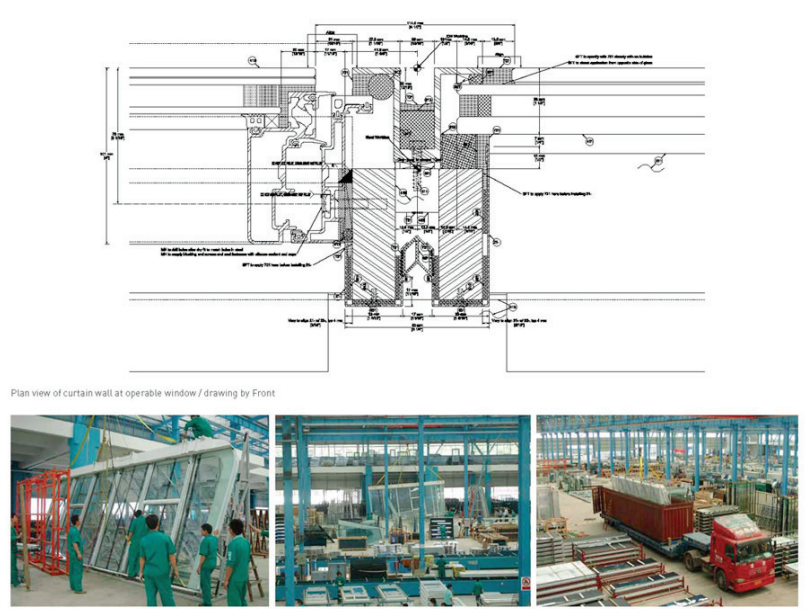

Figure 3: Highline 23 Residential. New York City, USA 2011

With China's significant role in curtain wall fabrication, changes in digital practices of these fabrication giants will need to be triggered by economic drivers of labor cost and quality control. The business model for many of the major manufacturers at this stage is in increasing the capacity of production such as through breakthroughs in glass size production and larger unitized sizes, than in developing new integration processes within their production line. The role of a digital façade model in China fabrication market is most effective in its automated output of 2D shop drawing of the customizable design.

\section{Digital Fabrication for Building Facades in Colombia}

First South American countries to introduce programming techniques for design and digital fabrication were Chile and Brasil between 2002 and 2006. Other countries, such as Peru and Colombia followed them since 2008. In contrast with the U.S. and Europe, where digital fabrication was developed primarily for industrial purposes, in South America these techniques were first adopted for experimentation on academic environments (Herrera, 2011).

Colombia, undergoing development, is exploring implementation of new technologies by local AEC industry, however, innovations in building façade design and fabrication are incipient. Higher costs of machinery vs. lower labor costs are among the main obstacles for the expansion of this technology. There are other factors such as resilience to adopt new technologies, lack of knowledge about advanced digital tools between designers and other cultural issues.

The use of low-weight façade systems, curtain wall included, is increasing within the local AEC industry. The appeal of these systems as well as shorter fabrication and installation schedules, are reasons for their expansion. Major façade vendors are using CNC machinery on their production lines, mostly for sectioning and drilling. Aluminum Composite Material panels (ACM) also requires $\mathrm{CNC}$ cutting and laser printers are used to print patterns over glazing panels.

At least four Fab Labs operate on major universities in the Country, but there is still a lot of unawareness about this theme among professionals and vendors. A few private studios are investigating the potential of this technology for the production of facades, often combining parametric tools with performance analysis in order to increase sustainability. Other studios focus their digital fabrication explorations on furniture and interior design.

Mazzanti Architects and Plan:B are two of the most active and recognized design offices in Colombia. They explored digital fabrication for customized facades in a number of recently built projects, using laser cutting techniques to produce panels for sunshading and space division. It is the case of the Sports Coliseums for South American Games (Medellín, 2009, Mazzanti + Plan:B), which is a large scale facility that integrates a number of fields for the practice of four different sports. Exterior corridors are separated from sport fields by a large set of perforated aluminum panels manufactured by a specialized company called Rolformados S.A. After receiving basic Autocad drawings produced by the project designers, as well as expected transparency rates for climate performance, this company used Rhinoceros/Grasshopper to produce final patterns and drive the laser cutting process. Structural elements for the façade system are made of stainless steel and panels are $2 \mathrm{~mm}$ gauge aluminum sheets. 


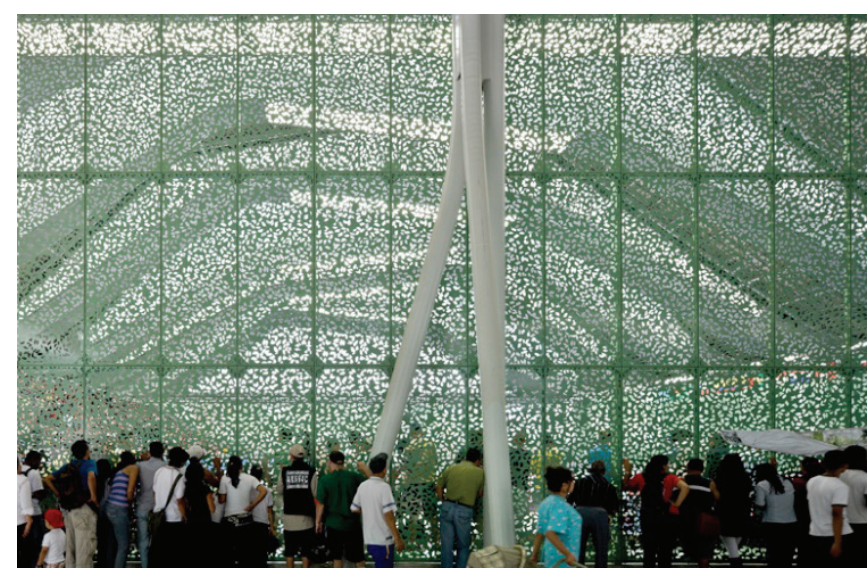

Figure 4: Sport Coliseums for South American Games. Medellin, 2009. Mazzanti. + Plan:B Archs. Retrieved from:

http://www.planbarquitectura.com/

Serial production of identical items remains as the prevailing paradigm for the construction industry in Colombia and there is a growing need for the optimization of production lines in order to compete with products coming from abroad (mostly from Asia), due to global marketing policies. Automation, interoperability and data exchanges play a key role on this optimization demand. Although the presented case correspond with a customized system developed locally, a common practice for high budget projects in the country is to import and install pre-fabricated systems. A wider analysis of the AEC industry in Colombia would help to understand how low labor costs vs. higher cost of technology represents an obstacle for the adoption of this technology.

\section{Conclusions}

Designers faced with demands to retain design autonomy within controlled fabrication costs are exploring the extents of how to automate their design models with fabrication parameters. Largescale projects with highly defined facade designs are often presented with cost-competitive fabricators in China that are less prepared for digital fabrication and more willing to increase workforce to meet fabrication needs. Technology adoption for façade fabrication in emerging construction markets in Asia and South America are lagging behind compared to fabrication methods in mature markets such as United States.

As pressures increase to consider sustainability in design as well as work processes, global practices will see extensive adoption of BIM to facilitate digital fabrication of the façade design. Conventional CAD systems took over one decade to become mainstream for project documentation in Colombia after they were adopted in US and Europe. BIM adoption in US was projected to be $50 \%$ based on a 2009 large-scale survey by McGraw Hill SmartReport. Growing labor and capital costs will also present incentives due to the potential value of digital fabrication, in budget and schedule control, pushing its global implementation to some extent for fabricators to stay competitive.

\section{References}

Carpo, M. (2011). The Alphabet and the Algorithm. Cambridge, Massachusetts: MIT Press

Carroll, C., Cross, P., Duan, X. (2008). Case Study: CCTV Building Headquarters \& Cultural Center. CTBUH Journal Issue III.

Herrera, P. (2011). Towards an identity Digital Fabrication in Latin America. Lecture at Symposium AA Visiting School: Politics of Fabrication Laboratory. Valparaiso, Chile, May 13th 2011

Iwamoto, L. (2009). Digital Fabrications. New York, NY: Princeton Architectural Press

Kolarevic, B. (2003). Architecture in the Digital Age: Design and Manufacturing. New York, NY: Taylor \& Francis

McGrawHill SmartMarket Report (2009). The Business Value of BIM: Getting to the Bottom Line.

Post, N. (2010). New York's Tallest Residential Tower Is Frank Gehry 'Demystified'. Engineering News-Record. March 29, 2010. McGrawHill

Synovate Report (2009)

The Steel Institute of New York / The Ornamental Metal Institute of New York. (2011). 8 Spruce Street. Metals in Construction. Spring 2011. New York, NY. 